\title{
THE VEGETATION TRENDS AND DRIVERS IN BEIJING-TIANJING-HEIBEI REGION FROM 1982 TO 2013 BASED ON TIME SERIES GIMMS NDVI3g
}

\author{
Liu Shuhan ${ }^{1, *}$, Tian Haijing ${ }^{2}$, Wang Xia ${ }^{1}$, Li Hongzhou $^{1}$, He Yun ${ }^{1}$ \\ ${ }^{1}$ Satellite Surveying and Mapping Application Center, National Administration of Surveying, Mapping and Geo-information, \\ Beijing, P.R. China - liush@ sasmac.cn; \\ ${ }^{2}$ Survey and Planning Institute of State Forestry Administration, Beijing, P.R. China - tianhaijing278@ 163.com
}

\begin{abstract}
KEY WORDS: GIMMS NDVI3g, Monitoring the changes of vegetation, Climate Change, Beijing-Tianjin-Hebei Region
\end{abstract}
\begin{abstract}
:
Vegetation plays a leading role in ecosystems. Plant communities are the main components of ecosystems. Green plants in ecosystems are the primary producers, and they provide the living organic matter for the survival of other organisms. The dynamics of most landscapes are driven by both natural processes and human activities. In this study, the growing season GIMMS NDVI3g and climatic data were used to analyse the vegetation trends and drivers in Beijing-Tianjin-Hebei region from 1982 to 2013 . Result shows that, the vegetation in Beijing-Tianjin-Hebei region shows overall restoration and partial degradation trend. The significant restoration region accounts for $61.5 \%$ of Beijing-Tianjin-Hebei region, while the significant degradation region accounts for $2.1 \%$. The dominant climatic factor for time series NDVI were analyzed using the multi-linear regression model. Vegetation growth in $17.9 \%$ of Beijing-Tianjin-Hebei region is dominated by temperature, $35.5 \%$ is dominated by precipitation, and $11.68 \%$ is dominated by solar radiance. Human activities play important role for vegetation restoration in Beijing-Tianjin-Hebei Region, where the large scale forest restoration programs are the main human activities, such as the three-north shelterbelt construction project, Beijing-Tianjin-Hebei sandstorm source control project and grain for green projects.
\end{abstract}

\section{INTRODUCTION}

Climate change, especially climate warming in modern times has attracted wide attention from governments, scientists and the public. For example, with the 2009 UN climate conference in Copenhagen, climate change is no longer a purely scientific issue, but rather a political issue in the international community. In the past 30 years, the climate of northeast Asia (China, Russia and Mongolia) has changed dramatically. The results show that the region is one of the regions with the strongest signal of global warming (Chase, T. N. et al., 2000) .

Terrestrial ecosystem is the life support system for sustainable development of human society, and vegetation is the link between the atmosphere, soil and water in terrestrial ecosystems (Ma and Frank, 2006) which plays an important role in the exchange of earth system material and energy and that is the most sensitive component to global change in terrestrial ecosystems. We can indicate climate change through changes in vegetation ecosystem (Cramer et al., 2001). The dynamic changes of vegetation can reflect the response of climate and non-climatic factors to some extent. Vegetation changes are not only affected by climate change, but also by non-climatic factors.

NDVI, (Normalized Difference Vegetation Index), . It is used to reflect vegetation productivity by using vegetation chlorophyll to reflect the near-infrared light and absorption of red band (Rouse et al., 1974). NDVI can better reflect vegetation's absorption capacity of photosynthetic effective radiation (Bunn, 2006). NDVI is very sensitive to the low vegetation coverage information in arid and semi-arid regions (Myneni et al., 1997), so NDVI can be used to reflect vegetation information in low vegetation coverage areas. Using time series remote sensing products, scholars have found significant recovery of vegetation in the global (Ichii et al., 2013) and regional scale (Harris et al., 2014).

People using long time series of remote sensing products analysis in the study of the global scale, Asia, and China regional vegetation change and driving factors, but also no scholar of vegetation change and driving factors of the Beijing-Tianjin-Hebei region detailed analysis on regional scale. This study analysed the region, the main purpose is: 1) Using the long time series remote sensing data of the Beijing-Tianjin-Hebei region from 1982 to 2013 to analyze the growth potential of the vegetation in the region for nearly 32 years; 2) Analyse the effects of climatic factors on vegetation changes in the region by using climatic factors such as temperature, precipitation and sunshine in the Beijing-Tianjin-Hebei region from 1982 to 2013; 3) Analyze the effects of human activities on the vegetation changes in the Beijing-Tianjin-Hebei region by combining the local ecological protection projects and other human activities.

\section{RESEARCH METHODS}

\subsection{Overview of the research area}

"Beijing-Tianjin-Hebei" region is China's "capital circle", including Beijing, Tianjin and Hebei province. Xi Jinping, general secretary of the CPC central committee, President of the CPC central committee and President of the central military commission, held a symposium in Beijing on February 26, 2014. Listen to the report on the coordinated development of the Beijing-Tianjin-hebei region and realizing the coordinated development of Beijing, Tianjin and Hebei is the need to create a new capital economic circle in the future and promote the innovation of regional development system and mechanism. It is necessary to explore and improve the layout and shape of urban agglomeration, and provide demonstration and model for 
the development of regional development. It is necessary to explore the effective path of ecological civilization construction and promote the coordination of population economic resources and environment. It is necessary to realize the advantages of Beijing-Tianjin-Hebei region, promote the development of bohai economic zone and promote the development of the northern hinterland. It is a major national strategy. We should stick to the complementarity, mutual benefit and speed up the development of a scientific and sustainable development path.

We found that the NDVI in the Beijing-Tianjin-Hebei region is more than 0.4 by analysing the average GIMMS NDVI3g of the vegetation growth season in the Beijing-Tianjin-Hebei region in 1982. This indicates that the Beijing-Tianjin-Hebei region is dominated by medium vegetation coverage and high vegetation coverage.

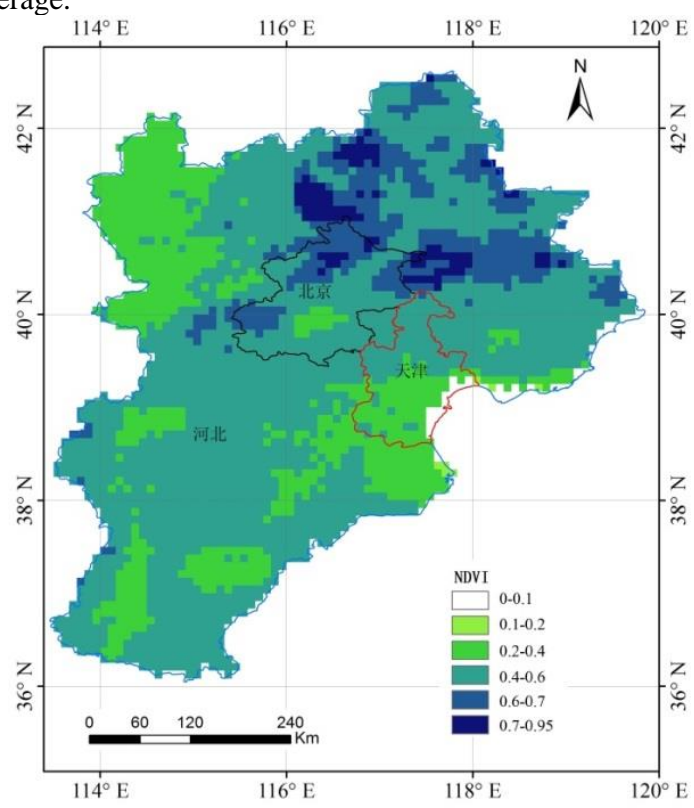

Figure 1 Spatial distribution of GIMMS NDVI3g in the

Beijing-Tianjin-Hebei region between 1982 and 2013.

\subsection{Data source}

GIMMS NDVI3g: AVHRR (advanced very high resolution radiometer) NDVI (normalized difference vegetation index) data is the longest continuous data set in the world at present, and it has gained wide attention both at home and abroad. In particular, GIMMS (global inventory modelng and mapping studies) NDVI data sets are characterized by long time series, extensive coverage, spatial and temporal comparison, strong vegetation dynamic change characterization ability, etc., which is the most widely used data set in AVHRR NDVI data which has been used a lot in regional and global scale vegetation dynamic change detection and genetic analysis, land degradation region identification, vegetation productivity simulation and carbon balance research. The understanding of vegetation dynamic change is improved.

Previous studies have shown that Global Inventory Modeling and Mapping Studies (GIMMS) NDVI data sets can be accurately applied to the study of global vegetation changes ${ }^{[4,13-15]}$. Using regional scale higher resolution remote sensing image or time series field measured data, and combined with local expert knowledge base to verify this vegetation change trend analysis and consistency analysis is very necessary. Based on the precise information of regional scale, this paper makes a cross-comparative analysis of the variation trend of different long-time series vegetation products in different ecosystems or different land use types which can provide a reliable reference for the study of vegetation change.

Climatological data: CRU TS3.2 climatic data set ${ }^{[16]}$ was used in the study. The monthly data of temperature, precipitation, cloud cover and evaporation from 1982 to 2013 were used and the difference between precipitation and evaporation is calculated to represent the net precipitation.

\subsection{Mann-kendall time series non-parametric estimation model}

In order to compare the linear regression model with time series based on least square method,

In this study, Mann-kendall non-parametric estimation model was used to simulate the trend of vegetation growth which is more powerful to prove the trend of vegetation growth at the same time. Mann-kendall non-parametric estimation slope can avoid the loss of time series data and the influence of data distribution patterns on the analysis results compared with the linear trend fitting based on least square method, it also can eliminate the disturbance of abnormal value in time series. Therefore, in the analysis of long time series data sets, the slope of non-parametric estimation is often used to detect the magnitude of the change trend. In this study, non-parametric Sen's trend test was used to improve trend identification and spatial autocorrelation and use Sen's slope to obtain the magnitude of the change trend of time series. The calculation formula of Sen's non-parametric estimation slope is as follows:

slope $=\operatorname{Median}\left(Q_{i}\right)=\operatorname{Median}\left(\frac{x_{j}-x_{i}}{j-I}\right)$ for $i=1, \cdots, N$

Among them: xi and xj respectively represent the cumulative NDVI value of vegetation growth season in year $i$ and $j(j>i)$ respectively. The Median represents the number of calculations. If $\mathrm{N}$ is odd, the calculation formula of slope is:

$$
\text { slope }=\operatorname{sort}(\mathrm{Q})_{(\mathrm{N}+1) / 2}
$$

If $\mathrm{N}$ is even, the calculation formula of slope is:

$$
\text { slope }=\frac{1}{2}\left(\operatorname{sort}(Q)_{\frac{N}{2}}+\operatorname{sort}(Q)_{\frac{N+2}{2}}\right)
$$

The significance test of time series trend needs to be done by Mann-kendall (MK) test method. This method is proposed by Mann and is mainly used to detect the change trend of detection time series. Mann-kendall slope and Mann-kendall trend test are combined to use as an important method for the analysis of long time series data trend which is widely used in the analysis of vegetation trend of long time series. The MK test is a non-parametric trend test, which is one of the most commonly used time series trend test methods. The MK test sample does not need to conform to a certain distribution, nor is it affected by a few abnormal values which is applicable to the data of the non-normal distribution. It is also widely used in remote sensing data analysis.

The significance level of the study was $p<0.05$, and if $p<0.05$, the change of NDVI was considered to be significant, otherwise the change of NDVI was not significant. 


\subsection{Regression analysis of NDVI and climate factors}

Temperature, solar radiation, water, combined with the growth of vegetation [16]. The correlation between NDVI and individual climatic factors was analysed by using the temperature, precipitation and cloud cover ratio in CRU TS3.2 climate data, and the correlation coefficient and significance level were calculated. The significance level of the study was $\mathrm{p}<0.05$, and if $\mathrm{p}<0.05$, the correlation between NDVI and climate factors was considered significant, otherwise the correlation between NDVI and climate factors was not significant.

Using the combination of NDVI and climatic factors (temperature, precipitation, sunshine) normalized multiple linear regression analysis and residual trend analysis method, the effects of climate and non-climatic factors on vegetation change were distinguished.

Use normalized multivariate linear regression analysis to analyse the common role of each factor on NDVI and their respective weights ${ }^{[21]}$. Climate factors (temperature, solar radiation, water) are usually interacting with each other, and the effects on vegetation are not independent. Analyse the common influence of temperature, solar radiation, water on NDVI and the weight of each factor.

$$
\frac{\mathrm{NDVI}-\overline{\mathrm{NDVI}}}{\sigma_{\mathrm{NDVI}}}=\beta_{0}+\beta_{1} \frac{\mathrm{CLM}_{1}-\overline{\mathrm{CLM}_{1}}}{\sigma_{1}}+\cdots+\beta_{\mathrm{n}} \frac{\mathrm{CLM}_{\mathrm{n}}-\overline{\mathrm{CLM}_{\mathrm{n}}}}{\sigma_{\mathrm{n}}}
$$

Where $\overline{\mathrm{NDVI}}$ is the average of NDVI for years $\sigma_{\mathrm{NDVI}}$, is the standard deviation of NDVI for many years, $\overline{\mathrm{CLM}_{i}}$ is the multi-year average of the ith climate factor, $\sigma_{i}$ is the standard deviation of the ith climate factor.

$\mathrm{F}$ is used to test the multivariate linear regression equation. If the significance level indicator $\mathrm{P}<0.05$, the correlation between NDVI and climate factors was significant.

\section{RESULTS}

3.1 Analyse of the change of vegetation in the Beijing-Tianjin-Hebei region from 1982 to 2013

In the study we used non-parametric estimation methods. Based on MATLAB, the change slope of NDVI in the annual vegetation growth season of $8 \mathrm{~km}$ resolution in Beijing-Tianjin-Hebei region and significance level (figure 2) was obtained. The regions with significant increase and significant decrease in NDVI were extracted (figure 3).

By analysing the change rate and significance level of NDVI in the Beijing-Tianjin-Hebei region from 1982 to 2013, the region showed a significant decrease in NDVI, which represents the degradation of vegetation. About $61.5 \%$ of the region showed a significant increase in NDVI, which represents the restoration of vegetation. This shows that from 1982 to 2013, the region showed the overall vegetation restoration and the emergence of local vegetation degeneration. The area of vegetation degeneration is mainly distributed in the east of the region

\subsection{Influence of human activities on the change of vegetation in Beijing-Tianjin-Hebei region}

The study on the relationship between vegetation cover and climate change has become an important part of global change research. China has been one of the most closely watched areas of global change research for one of the regions with the strongest signs of global warming. It is of great significance to analyse the impacts of climate factors on China's vegetation changes. Temperature, radiation and water interaction are combined with terrestrial vegetation changes (Churkina G 1998). The average temperature of vegetation growing season was selected as the temperature index, the precipitation is selected as the index of water response, The coverage ratio of cloud is selected as the index of radiation intensity in the study.
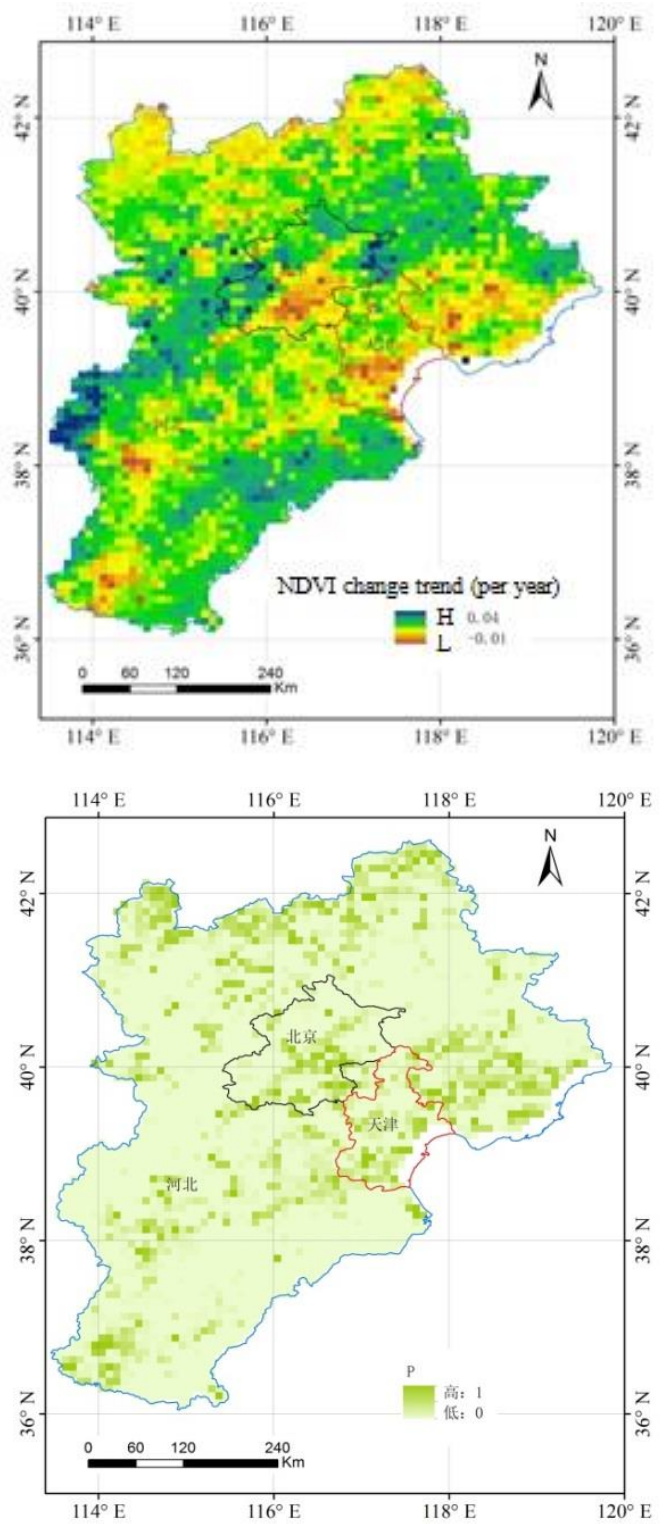

Figure 2 change slope of GIMMS NDVI (left) and significance level (right) of the vegetation growing season in the Beijing-Tianjin-Hebei region from 1982 to 2013

In the study, we used the normalized multiple linear regression analysis to analyse the common effects of various climatic factors on NDVI. The regression coefficient and significance level of normalized multivariate linear regression were calculated. Three climatic factors, including temperature, precipitation and cloud cover, were considered in the study. Select the factor with the highest regression coefficient as the 
dominant climate factor affecting the NDVI of the pixel $(8 \mathrm{~km})$. If the significance level of normalized multiple linear regression analysis is $\mathrm{p}<0.05$, it is considered that the pixel is significantly affected by the multi climate factor. Finally, the dominant climate factor distribution of GIMMS NDVI3g in the Beijing-Tianjin-Hebei region was influenced from 1982 to 2013, as shown in figure 4.

The results show that temperature is the dominant climate factor influencing the trend of GIMMS NDVI3g time series in $17.9 \%$ of the region. The precipitation - evapotranspiration is the dominant climate factor influencing the trend of GIMMS NDVI3g time series in $35.5 \%$ of the region. The cloud coverage ratio is the dominant climate factor affecting the trend of GIMMS NDVI3g time series in 5.5\% of the region. From 1982 to 2013, precipitation was the major climatic factor affecting the vegetation change in the Beijing-Tianjin-Hebei region.

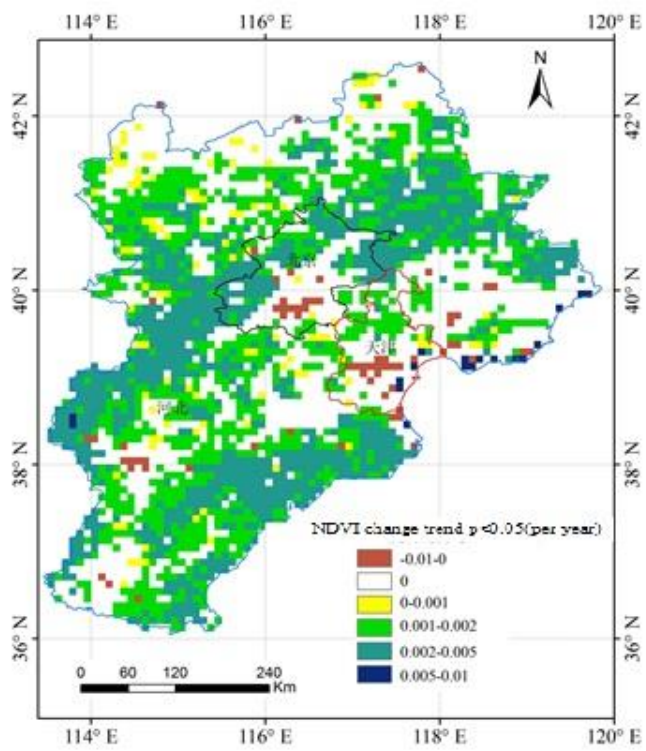

Figure 3 Significant variation trend distribution of GIMMS NDVI in the Beijing-Tianjin-Hebei region between 1982 and 2013

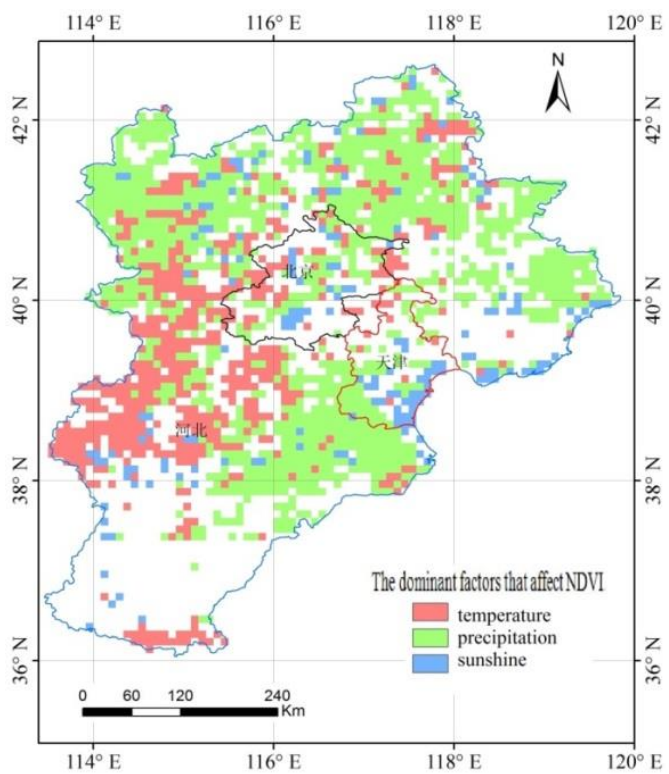

Figure 4 influences the dominant climatic factors of GIMMS NDVI3g in the Beijing-Tianjin-Hebei region from 1982 to

$$
2013 .
$$

\subsection{Analysis of the impact of human activities on vegetation growth in the Beijing-Tianjin-Hebei region}

In the study, we considered that NDVI was significantly changed, but the regions with insignificant correlation between NDVI and climate factors were corresponding to the significant changes in vegetation caused by human activities. The region that GIMMS NDVI3g significantly increased while NDVI and multi-climatic factors regression analysis was not significant from 1982 to 2013 is defined as the vegetation restoration area caused by human activities. The region that GIMMS NDVI3g significantly decreased, while NDVI and multi-climatic factors regression analysis was not significant from 1982 to 2013 is defined as a region of significant vegetation degradation caused by human activities. The result is shown in figure 5 . The results show that the vegetation recovery area caused by human activities from 1982 to 2013 accounted for $21.0 \%$ of the region, and the vegetation significantly degraded by human activities accounted for $0 \%$ of the region.

The Beijing-Tianjin-Hebei region is a key implementation area for China's large-scale forestry ecological projects, such as the three-north shelterbelt project, the Beijing-Tianjin wind-sand source control project, and the conversion of farmland to forestry. The implementation of a series of large-scale forestry ecological projects is the most important factor affecting the vegetation restoration in the region. This indicates that forestry ecological engineering has achieved remarkable results in the region.

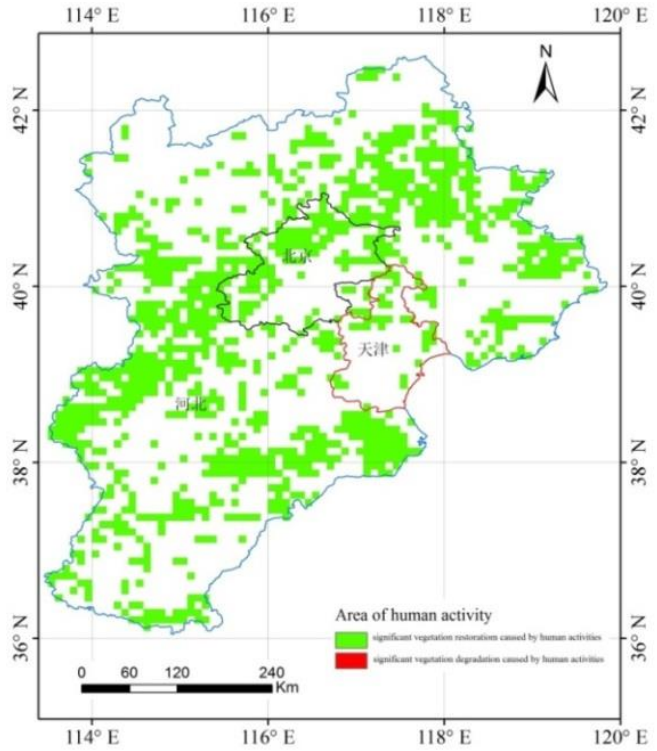

Figure 5 Distribution of the influence of human activities on vegetation changes in the Beijing-Tianjin-Hebei region.

\section{Conclusion}

In the study, we used the average NDVI data in vegetation growth season and climatic data of the Beijing-Tianjin-Hebei region from 1982 to 2013. The change of vegetation in the region and the main driving factors were analysed. The region is dominated by medium vegetation coverage and high vegetation coverage. Between 1982 and 2013, 2.1\% of the region 
presented vegetation degradation, and $61.5 \%$ of the regions showed vegetation restoration. In the Beijing-Tianjin-Hebei region, $17.9 \%$ of the region, temperature is the dominant climate factor influencing the trend of GIMMS NDVI3g time series. $35.5 \%$ of the region, precipitation is the dominant climate factor affecting the trend of GIMMS NDVI3g time series. $35.5 \%$ of the region, the cloud coverage ratio is the dominant climate factor affecting the trend of GIMMS NDVI3g time series.

From 1982 to 2013, the vegetation significantly recovered from human activities accounted for $21.0 \%$ of the region, and the vegetation significantly degraded by human activities accounted for $0 \%$ of the region. The Beijing-Tianjin-Hebei region is a key implementation area for China's large-scale forestry ecological projects, such as the three-north shelterbelt project, the Beijing-Tianjin wind-sand source control project, and the conversion of farmland to forestry. The implementation of a series of large-scale forestry ecological projects is the most important factor affecting the vegetation restoration in the region. This indicates that forestry ecological engineering has achieved remarkable results in the region.

\section{ACKNOWLEDGEMENTS}

This work was supported by the High Resolution Images Surveying and Mapping Application System of China (Project No. AH1601-11)

\section{REFERENCES}

Chase, T. N., Pielke Sr, R. A., Knaff, J. A., Kittel, T. G., \& Eastman, J. L. 2000. A comparison of regional trends in 1979-1997 depth-averaged tropospheric temperatures. International Journal of Climatology, 20(5), 503-518.

Ma, M., \& Frank, V. 2006. Interannual variability of vegetation cover in the Chinese Heihe River Basin and its relation to meteorological parameters. International Journal of Remote Sensing, 27(16), 3473-3486.

Cramer, W., Bondeau, A., Woodward, F. I., Prentice, I. C., Betts, R. A., Brovkin \& Kucharik, C. 2001. Global response of terrestrial ecosystem structure and function to $\mathrm{CO} 2$ and climate change: results from six dynamic global vegetation models. Global change biology, 7(4), 357-373.

Rouse, J. W., Haas, R.H., Schell, J.A, et al. Monitoring vegetation systems in the great plains with ERTS. 1974, Third Earth Resources Technology Satellite-1 Symposium- Volume I:Technical Presentations, NASA SP-351, 09.

Baret, F. \& G. Guyot. Potentials, and limits of vegetation indices for LAI and APAR assessment. 1991, Remote Sensing of the Environment, 35, 161-173.

Bunn A G, G. S. J. 2006. Trends in satellite-observed circumpolar photosynthetic activity from 1982 to 2003: the influence of seasonality, cover type and vegetation density. Earth Interactions, 10, 1-19.
Myneni R B, K. C. D., Tucker C J, et al.1997. Increased plant growth in the northern high latitudes from 1981 to 1991. Nature, 386, 698-702.

Nemani RR, K. C., Hashimoto H, Jolly WM, et al. 2003. Climate-driven increases in global terrestrial net primary production from 1982 to 1999. Science, 300, 1560-1563.

Zhou L M, T. C. J., Kaufmann R K, Slayback D, et al. 2001. Variations in northern vegetation activity inferred from satellite data of vegetation index during 1981 to 1999. Journal of Geophysical Research: Atmospheres (1984-2012), 106, 20069_20083.

Ichii, K., Kondo, M., Okabe, Y. , et al. 2013.Recent changes in terrestrial gross primary productivity in Asia from 1982 to 2011. Remote Sensing of Environment, 5, 6043-6062.

Tian H J, C. C. X., Chen W, et al. 2015. Response of vegetation activity dynamic to climatic change and ecological restoration programs in Inner Mongolia from 2000 to 2012. Ecological Engineering, 82, 276-289.

Wu Z, W. J., Liu J, et al. 2013. Increasing Terrestrial Vegetation Activity of Ecological Restoration Program in the Beijing-Tianjin Sand Source Region of China., Ecological Engineering, 52, 276-289.

Slayback D A, P. J. E., Los S O, Tucker C J, 2003. Northern hemisphere photosynthetic trends 1982 - 99. Global Change Biology, 9, 1-15.

Tucker C J, P. J. E., Brown M E, Slayback D A, et al. 2005. An extended AVHRR 8-KM NDVI dataset compatible with MODIS and SPOT vegetation NDVI data., International Journal of Remote Sensing, 26, 4485-4498.

Beck H E, M. T. R., van Dijk AIJM, Schellekens J, et al. 2011. Global evaluation of four AVHRR-NDVI data sets: Intercomparison and assessment against Landsat imagery. Remote Sensing of Environment, 115, 2547-2563.

Harris I, J.P.D., Osborn T J, Lister D H. Updated high-resolution grids of monthly climatic observations-the CRU TS3,2014.

Hua Yongchun. 2010. Monitoring of vegetation changes based on MODIS Beijing-Tianjin wind and sand source project. Doctoral dissertation, Beijing forestry university.

Liu Donghao. 2000. Planting trees in northwest China should follow the natural and economic law. China's agricultural resources and regionalization.21 (2) : 8-10.

Yin He, Li Zhengguo, Wang Zhaolin, et al., 2011. Evaluation of desertification in Inner Mongolia based on time series 
The International Archives of the Photogrammetry, Remote Sensing and Spatial Information Sciences, Volume XLII-3, 2018 ISPRS TC III Mid-term Symposium "Developments, Technologies and Applications in Remote Sensing", 7-10 May, Beijing, China

vegetation characteristics. Journal of geography, 66(5): 653-661.

CAI Bofeng, Yu Rong., 2009. Research progress and evaluation of long-term trend characteristics of vegetation based on remote sensing. Journal of remote sensing,(006): 1170-1186.

Liu, Y., \& Lei, H.,2015. Responses of natural vegetation dynamics to climate drivers in China from 1982 to 2011. Remote Sensing, 7(8), 10243-10268. 